\title{
Toxicity-based assessment of the treatment performance of wastewater treatment and reclamation processes
}

\author{
Dongbin Wei*, Zhuowei Tan, Yuguo Du \\ State Key Laboratory of Environmental Chemistry and Ecotoxicology, Research Center for Eco-Environmental Sciences, \\ Chinese Academy of Sciences, Beijing 100085, China. E-mail: weidb@ rcees.ac.cn
}

Received 05 August 2011; revised 13 October 2011; accepted 18 October 2011

\begin{abstract}
The reclamation and reuse of wastewater is one of the possible ways to relieve the serious fresh water resource crisis in China. Efficient reclamation treatment technologies ensure the safe reuse of reclaimed water. In order to screen out and evaluate technologies appropriate for reclamation treatment, a great deal of efforts have been brought to bear. In the present study, a toxicity-based method including a Photobacterium phosphoreum test for acute toxicity and SOS/umu test for genotoxicity, accompanied by the traditional physicochemical parameters DOC (dissolved organic carbon) and $\mathrm{UV}_{254}$ (absorbance at $254 \mathrm{~nm}$ ), was used to measure the treatment performance of different reclamation processes, including the anaerobic-anoxic-oxic biological process $\left(\mathrm{A}^{2} \mathrm{O}\right)$ and subsequent physical/chemical reclamation processes (ultrafiltration, ozonation, chlorination). It was found that for the secondary effluent after the $\mathrm{A}^{2} \mathrm{O}$ process, both the toxicity and physicochemical indices had greatly decreased compared with those of the influent. However, chemical reclamation processes such as ozonation and chlorination could possibly raise toxicity levels again. Fortunately, the toxicity elevation could be avoided by optimizing the ozone dosage and using activated carbon after ozonation. It was noted that by increasing the ozone dosage to $10 \mathrm{mg} / \mathrm{L}$ and employing activated carbon with more than 10 min hydraulic retention time, toxicity elevation was controlled. Furthermore, it was shown that pre-ozonation before activated carbon and chlorination played an important role in removing organic compounds and reducing the toxicity formation potential. The toxicity test could serve as a valuable tool to evaluate the performance of reclamation processes.
\end{abstract}

Key words: wastewater reclamation; acute toxicity; genotoxicity; toxicity assessment

DOI: $10.1016 / \mathrm{S} 1001-0742(11) 60860-7$

\section{Introduction}

Uneven distribution of water resources, rapid population increase, a climate with frequent droughts, and heavy water pollution accompanying rapid economical development, have combined to create serious water resource scarcity and water quality deterioration, which is of great contemporary concern for municipalities, industries, agriculture, and the environment in many parts of the world in recent decades (Asano et al., 2007). The situation of water resource shortage in China is a typical case in point, especially in northern China, where the water resource per capita is only $1 / 40$ of the world average level (World Bank, 2009). Wastewater reclamation and reuse has been proven to be an effective pathway to relieve the fresh water resource shortage crisis, and has drawn more and more attention as an integral part of water resource management (Chu et al., 2004). However, potential damage to human health and the ecological system could become one of most pressing issues during long-term reuse of reclaimed water, because there are many kinds of toxic chemicals, excessive

\footnotetext{
* Corresponding author. E-mail: weidb@ rcees.ac.cn
}

nutrient elements, and pathogens remaining in wastewater which the traditional reclamation treatment processes cannot completely remove. The cumulative effect of toxic chemicals remaining in reclaimed water could increase potential risk to human health and ecological systems during long-term reuse (Asano et al., 2007; Hu et al., 2002).

As for reclamation treatment technologies, ozone, due to its strong oxidation potential, is widely used for disinfection, decoloration, and decomposition of organic compounds. Takanashi et al. (2002) found that ozone treatment was effective in removing mutagen precursors from wastewater. Activated carbon, with its strong adsorption capacity for organic compounds, is another popular technique for eliminating organic contaminants in water treatment processes individually or combined with other treatment processes, such as ozonation (Reungoat et al., 2010; Sánchez-Polo et al., 2006). Additionally, to reduce the pathogenetic risk, disinfection of reclaimed water for reuse using chlorine or other agents is generally required. However, the adverse effects of chlorination have caused concerns over the formation of hazardous disinfection by-products (DBPs), and many studies have reported 
that chlorination disinfection enhanced acute toxicity and genotoxicity (Cao et al., 2009; Wang et al., 2005; Wei et al., 2006). Therefore, a reasonable measurement of the safety of reclaimed water and the treatment efficiency of advanced treatment processes becomes an emergent and compulsory task.

Hazards or risks of polluted environmental water and efficiencies of water treatment processes are traditionally measured with physicochemical parameters, e.g., chemical oxygen demand (COD) and total organic carbon (TOC). However, more and more reports have shown that physicochemical analysis alone cannot sufficiently and effectively evaluate the safety of environmental water samples, because it is impossible to account for all of the chemicals, and to reflect the synergistic or antagonistic interactive effects of multiple chemicals co-existing in environmental elements (Fernández et al., 2005; Juvonen et al., 2000). Fortunately, biological toxicity tests, which are useful tools for integrating the effects of all the bioavailable contaminants and of their interactions, are widely used not only to evaluate the safety of single and multiple chemicals, but also of environmental samples (Hernando et al., 2005). For example, the US Environment Protection Agency (US EPA, 1991) proposed "Whole Effluent Toxicity" using a toxicity test battery to evaluate and manage the discharge of wastewater, and other countries introduced similar regulations and methods as well (UKEA, 2006). Recently, bioassays have also been applied to evaluate the performance of wastewater treatment (Cao et al., 2009; Araújo et al., 2005). However, most studies only evaluated the toxicity of water samples or the performance of treatment processes using a relative inhibition rate or toxicity unit, which made comparisons difficult (Macova et al., 2010). Therefore, the evaluation of the safety of water quality and comparison of the efficiency of wastewater treatment technologies using toxicity test results is still a bottleneck in this area.

In this study, two typical toxicity tests were selected, acute toxicity and genotoxicity respectively based on the Photobacterium phosphoreum test and SOS/umu test, and a simple assessment method based on toxicity tests was explored. With this method, the removal performance of ecological toxicity during $\mathrm{A}^{2} \mathrm{O}$ wastewater treatment processes and advanced wastewater reclamation processes, including ozonation with and without activated carbon followed by chlorination, was evaluated respectively. The results will be useful for the selection of suitable treatment technologies to reclaim wastewater effluent for safe reuse.

\section{Materials and methods}

\subsection{Water sampling}

Wastewater samples were collected from a wastewater treatment plant (WWTP) connected to a reclamation treatment plant (RTP) in Beijing, China. The physicochemical parameters, including 5-day biochemical oxygen demand $\left(\mathrm{BOD}_{5}\right)$, chemical oxygen demand $(\mathrm{COD})$, suspended solids (SS), ammonia nitrogen $\left(\mathrm{NH}_{4}{ }^{+}-\mathrm{N}\right)$, and total phos-
Table 1 Water quality characteristics of WWTP and RTP

\begin{tabular}{lrrrrr}
\hline & \multicolumn{2}{c}{ WWTP } & & \multicolumn{2}{c}{ RTP } \\
\cline { 2 - 3 } \cline { 5 - 6 } & Influent & Effluent & & Influent & Effluent \\
\hline $\mathrm{BOD}_{5}(\mathrm{mg} / \mathrm{L})$ & 149.5 & 4.6 & & 4.9 & 2.2 \\
$\mathrm{COD}_{\mathrm{Cr}}(\mathrm{mg} / \mathrm{L})$ & 337.9 & 40.6 & & 35.7 & 24.4 \\
$\mathrm{SS}(\mathrm{mg} / \mathrm{L})$ & 150.0 & 10.3 & & 6.3 & 2.0 \\
$\mathrm{NH}_{4}^{+}-\mathrm{N}(\mathrm{mg} / \mathrm{L})$ & 39.8 & 2.2 & & 1.4 & 1.2 \\
$\mathrm{TP}(\mathrm{mg} / \mathrm{L})$ & 6.4 & 0.6 & & 0.5 & 0.4 \\
\hline
\end{tabular}

WWTP: wastewater treatment plant; RTP: reclamation treatment plant.

phate (TP), of water samples are shown in Table 1. Twenty-four hour composite, flow-proportional samples of wastewater were collected from the outlet of WWTP primary sedimentation (sample A), outlet of anaerobic process (sample B), outlet of anoxic process (sample $\mathrm{C}$ ), outlet of oxic process (sample D), and outlet of secondary sedimentation (sample E). Samples from the outlet of each treatment process at the RTP: ultrafiltration, ozonation and chlorination, were collected and marked as samples F, $\mathrm{G}$ and $\mathrm{H}$, respectively. Meanwhile, a large volume of secondary sedimentation effluent (approximately 100 L) from the WWTP was collected for further benchscale studies on optimizing the operational conditions of ozonation, combined ozone and activated carbon process (abbreviated as $\mathrm{O}_{3}-\mathrm{AC}$ ), and chlorination processes. The effluent of each bench reclamation process was collected as well and marked as samples G' and H', samples G' and $\mathrm{H}^{\prime}$, respectively. The scheme of the treatment processes in the WWTP and RTP is shown in Fig. 1, along with the sampling locations. All samples were delivered to the laboratory, kept in $4^{\circ} \mathrm{C}$ refrigerator for pretreatment and tested within one day. The $100 \mathrm{~L}$ secondary effluent for bench-scale studies was divided into subsamples and stored in a sample bank $\left(-20^{\circ} \mathrm{C}\right)$ for further experiments carried out within one month.

\subsection{Pretreatment process}

Each sample $(1.0 \mathrm{~L})$ was filtered through a $0.7-\mu \mathrm{m}$ glass fiber filter (Whatman GF/F), followed by flowing through two pre-conditioned cartridges in tandem, an Oasis HLB cartridge (6 cc/500 mg, Waters, USA) and Sep-pak Vac $\mathrm{C}_{18}$ cartridge $(6 \mathrm{cc} / 500 \mathrm{mg}$, Waters, USA), using a solid phase extraction apparatus (Visiprep DL SPE, Supelco, USA) and a vacuum pump (DOA-P504-BN, Gast, USA) at $10 \mathrm{~mL} / \mathrm{min}$. Oasis HLB and Sep-pak Vac $\mathrm{C}_{18}$ cartridges have been well-studied and proven to adsorb many kinds of organic micropollutants in water or other environmental media, and have been widely applied to recover agricultural chemicals (Economou et al., 2009), pharmaceuticals (Vazquez-Roig et al., 2010; Huerta-Fontela et al., 2010), endocrine-disruptors (Pedrouzo et al., 2009), and brominated flame retardants (Ramos et al., 2007) from complex environmental water samples. The HLB and $\mathrm{C}_{18}$ cartridges were respectively eluted with $10 \mathrm{~mL}$ acetone at $2.0 \mathrm{~mL} / \mathrm{min}$. The acetone eluates were then mixed in a calibrated centrifuge tube and dried under nitrogen gas purge at $300 \mathrm{~mL} / \mathrm{min}$ in a water bath at $35^{\circ} \mathrm{C}$. Fifty microliter DMSO was added to dissolve organic components and used as a stock solution for toxicity tests. Five solutions 


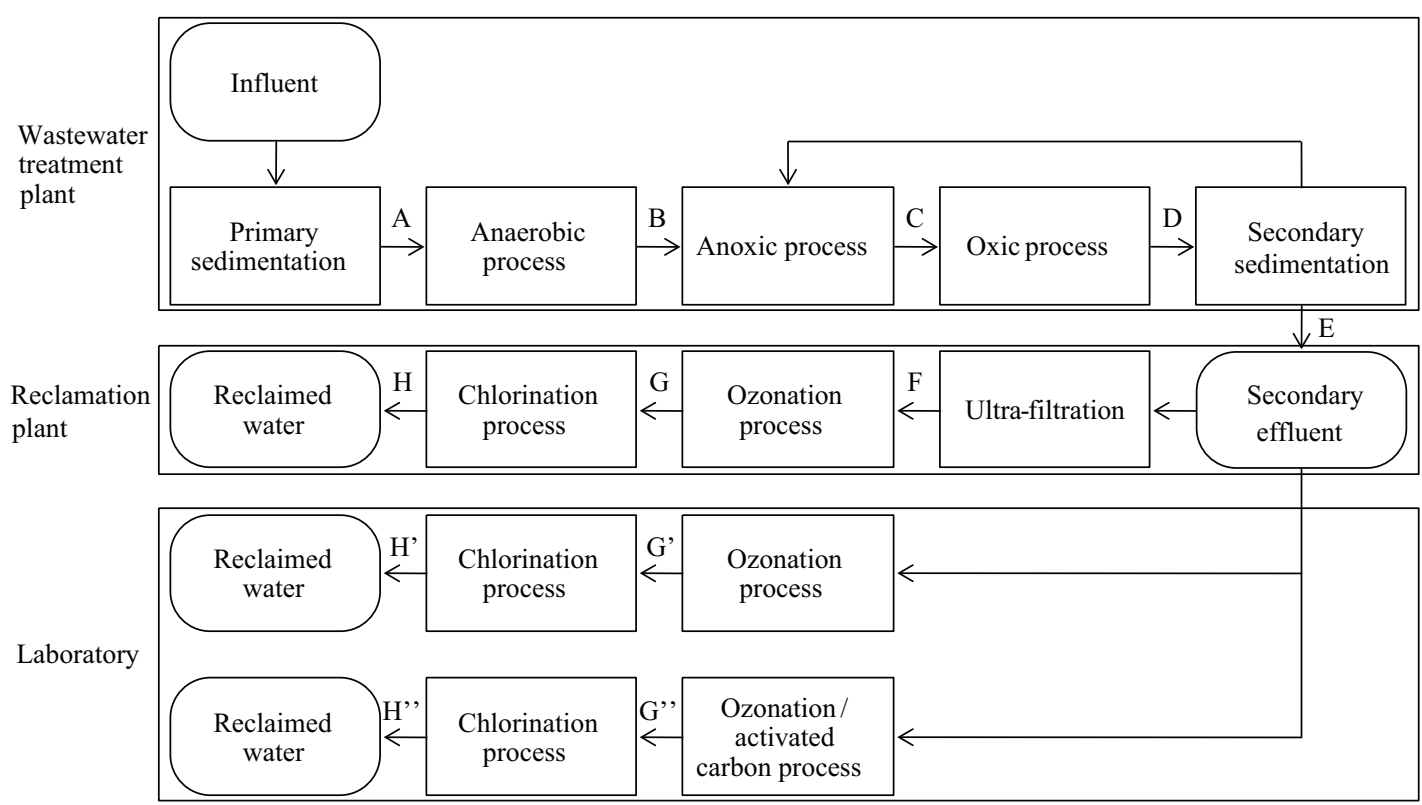

Fig. 1 Scheme of wastewater reclamation processes and map of water sampling.

with different concentrations (240-, 120-, 60-, 30-, and 15fold concentrated) were prepared for toxicity exposure.

\subsection{Ozonation process}

A transparent PVC (polyvinylidene chloride) column $(\phi 60 \mathrm{~mm} \times 1.5 \mathrm{~m})$ was used as an ozonation reactor, with a sintered quartz sand bottom plate for ozone dispersal. Two grams per hour of ozone was provided with an ozonizer (OS-1N, Mitsubishi, Japan). The secondary effluent was continuously pumped into the PVC column, and ozone was regulated by the voltage of the ozonizer. The ozone dosages of $0,5,10$, and $15 \mathrm{mg} / \mathrm{L}$ and contact times of 0 , 5, 10, 15, and $20 \mathrm{~min}$ were controlled by adjusting the pump flow rate. After the ozonation, the water samples were discharged into a water-box with an aerator to remove residual ozone and then taken for further experiments. The ozone dose was calculated with the method described by Cao et al. (2009).

\subsection{Combined ozone and activated carbon processes}

The water sample collected in the water-box after the ozonation process was pumped into another transparent PVC column $(\phi 60 \mathrm{~mm} \times 1.5 \mathrm{~m})$ filled with fresh activated carbon (ZJ-15 Model, $\phi 1 \mathrm{~mm} \times 2-3 \mathrm{~mm}$, Taiyuan Xinhua Ltd., China). In order to optimize the operational parameters, the ozone dosages were set to $0,5,10$, and 15 $\mathrm{mg} / \mathrm{L}$, and the contact times were set to $10,20,30$, and 45 min, respectively. Water samples after the ozone-activated carbon system were taken and pretreated for toxicity tests.

\subsection{Chlorination process}

A $5.0 \mathrm{~g} / \mathrm{L}$ chlorine stock solution was prepared by diluting sodium hypochlorite (Wako Ltd., Japan) with ultrapure water (Milli-Q Reference Water Purification System, Millipore Corp., USA). One liter of water sample, pretreated with the ozonation process or combined $\mathrm{O}_{3}$-AC process, was added into a $1 \mathrm{~L}$ of borosilicate glass bottle, and a given volume of the stock chlorine solution was added, mixed and placed for $0.5 \mathrm{hr}$ at ambient temperature $\left(20^{\circ} \mathrm{C}\right)$ for chlorination. A $0.025 \mathrm{~mol} / \mathrm{L}$ of sodium sulfite solution was added to quench the reaction and remove residual free chlorine, and the effluent was collected for further experiments.

\subsection{Acute toxicity test}

The Photobacterium photosphoreum acute toxicity test quantifies the decrease in light emission after exposure to toxic pollutants (SEPA, 1995). The test instrument (DXY2 Model Toxicity Analyzer) was made by the Institute of Soil Science, Chinese Academy of Sciences, Nanjing, China. The bacteria $P$. photosphoreum straus, was also provided as a freeze-dried powder by the same institute. The water samples after solid phase extraction were diluted into a series of exposure solutions, and $\mathrm{Hg}^{2+}$ with different concentrations was tested as a positive control. In the acute toxicity test, all samples including water samples and positive controls were tested in triplicate.

\subsection{SOS/umu genotoxicity test}

The genotoxicity effects of concentrated water samples were determined with the SOS/umu test (ISO13829, 2000; Oda et al., 1985). Salmonella typhimurium TA1535/pSK1002 in the SOS/umu test carrying an umuClacZ fusion gene on multicopy plasmid pSK1002 was a generous gift from Prof. Y. Oda (Osaka Prefectural Institute of Public Health, Japan). Briefly, the overnight bacterial culture was diluted 10 times with fresh TGA medium and incubated at $37^{\circ} \mathrm{C}$ for $1.5 \mathrm{hr}$ with shaking (130 r/min) until the bacteria reached the exponential growth phase. The test was performed on a microplate with the incubation mixture consisting of $180 \mu \mathrm{L}$ concentrated water sample, $20 \mu \mathrm{L}$ of $10 \times$ TGA and $70 \mu \mathrm{L}$ of bacterial culture (content of DMSO was ca. 1\%). The microplate was incubated at $37^{\circ} \mathrm{C}$ for $2 \mathrm{hr}$ with shaking $(130 \mathrm{r} / \mathrm{min})$; the incubation mixture was then diluted 10 times with fresh TGA medium and incubated for an additional $2 \mathrm{hr}$. The 
bacterial growth factor $(G)$ was determined by measuring the absorbance at $600 \mathrm{~nm}$, and calculated by Eq. (1):

$G=\frac{\mathrm{OD}_{600 \text {-sample }}-\mathrm{OD}_{600 \text {-blank }}}{\mathrm{OD}_{600 \text {-control }}-\mathrm{OD}_{600 \text {-blank }}}$

Absorption was measured at $420 \mathrm{~nm}$ using a reference solution without bacteria, and induction ratio (IR) was calculated by Eq. (2):

$\mathrm{IR}=\frac{1}{G} \times \frac{\mathrm{OD}_{420 \text {-sample }}-\mathrm{OD}_{420 \text {-blank }}}{\mathrm{OD}_{420 \text {-control }}-\mathrm{OD}_{420 \text {-blank }}}$

When an induction ratio was more than 1.5 , the sample was considered as genotoxic (ISO13829, 2000). 4-Nitroquinoline-1-oxide (4-NQO) was used as a positive control, TGA was used as the negative control, and a $1 \%$ DMSO aqueous solution was used as solvent control. In the genotoxicity test, all samples including water samples and positive control were tested in triplicate.

\subsection{Proposal of toxicity assessment index}

To conveniently evaluate the treatment performance of different reclamation processes, a simple toxicity assessment index was calculated. As mentioned above, for each toxicity test, dose-response curves were obtained for both the positive control sample and water sample at different concentrations. Based on their dose-response curves, the toxicity index could be obtained. Unlike the traditional method, the dose-response curve in this study was expressed using different parameters. Using the genotoxicity test as an example, for positive control substance 4-NQO, the $X$-axis of the dose-response curve is represented by the absolute mass of 4-NQO $(\mu \mathrm{g})$ in the test well, in lieu of concentration (e.g., mg/L). For water samples, the $X$-axis is represented by the converted volume of the original water sample (L) in the test well, in lieu of concentration factor. The $Y$-axis, similar to the traditional method, is represented by the induction ratio. The slope of the doseresponse curve for 4-NQO is marked as $S_{4-\mathrm{NQO}}$, and that for the water sample is marked as $S_{\text {Sample. Therefore, }}$ the ratio of $S_{\text {Sample }}$ to $S_{4-\mathrm{NQO}}$ representing the converted concentration of 4-NQO in the original water sample $(\mu \mathrm{g} / \mathrm{L})$, is used as a toxicity assessment index to compare the toxicity effect of tested water samples and evaluate the treatment performance of reclamation processes. The converted concentration of $\mathrm{Hg}^{2+}$ for the acute toxicity test is expressed as $C_{\mathrm{Hg}^{2+}}$, and the converted concentration of 4-NQO for the genotoxicity test is expressed as $C_{4-\mathrm{NQO}}$; higher $C_{\mathrm{Hg}^{2+}}$ and $C_{4-\mathrm{NQO}}$ represent stronger toxicity effects.

\section{Results and discussion}

\subsection{Toxicity changes during the traditional wastewater treatment processes}

The toxicity tests of all water samples collected from the $\mathrm{A}^{2} \mathrm{O}$ biological wastewater treatment processes and physical/chemical reclamation treatment processes were carried out by preparing a series of concentrated exposure solutions, and the corresponding effects of acute toxicity and genotoxicity were described as $C_{\mathrm{Hg}^{2+}}$ and $C_{4-\mathrm{NQO}}$, respectively. As shown in Fig. $2 \mathrm{a}, C_{\mathrm{Hg}^{2+}}$ decreased from 5.13 to $1.10 \mu \mathrm{g} / \mathrm{L}$ and $C_{4-\mathrm{NQO}}$ decreased from 19.12 to 3.72 $\mu \mathrm{g} / \mathrm{L}$ after wastewater treatment with $\mathrm{A}^{2} \mathrm{O}$ and secondary sedimentation processes in the WWTP. However, in the RTP, the ultrafiltration process did not change the toxicity characteristics of the water samples, and the ozonation and chlorination processes obviously increased toxicity. The $C_{\mathrm{Hg}^{2+}}$ increased from 1.09 to $2.03 \mu \mathrm{g} / \mathrm{L}$, and $C_{4-\mathrm{NQO}}$ increased from 3.45 to $4.35 \mu \mathrm{g} / \mathrm{L}$ after the ozonation and chlorination processes. Meanwhile, changes in DOC and $\mathrm{UV}_{254}$ were monitored during the $\mathrm{A}^{2} \mathrm{O}$ biological wastewater treatment and reclamation treatment processes, and the results are shown in Fig. 2b. The DOC decreased from 34.32 to $19.93 \mathrm{mg} / \mathrm{L}$ after $\mathrm{A}^{2} \mathrm{O}$ treatment processes, and $\mathrm{UV}_{254}$ decreased from 15.2 to $7.2 \mathrm{~m}^{-1}$ correspondingly, which is consistent with previous reports (Katsoyiannis and Samara, 2007; Mendonça et al., 2009). However, DOC exhibited no further decrease during subsequent ultrafiltration, ozonation and chlorination processes, and $\mathrm{UV}_{254}$ showed a similar trend except that a decrease was observed in the chlorination process. These experiments suggested that ozonation and chlorination processes could slightly decrease the physicochemical indices such as DOC (from 14.17 to $13.49 \mathrm{mg} / \mathrm{L}$ ) and $\mathrm{UV}_{254}$ (from 6.9 to $4.5 \mathrm{~m}^{-1}$ ), but also could cause toxicity elevation and increase risk on water reuse (Wei et al., 2006); therefore, more attention
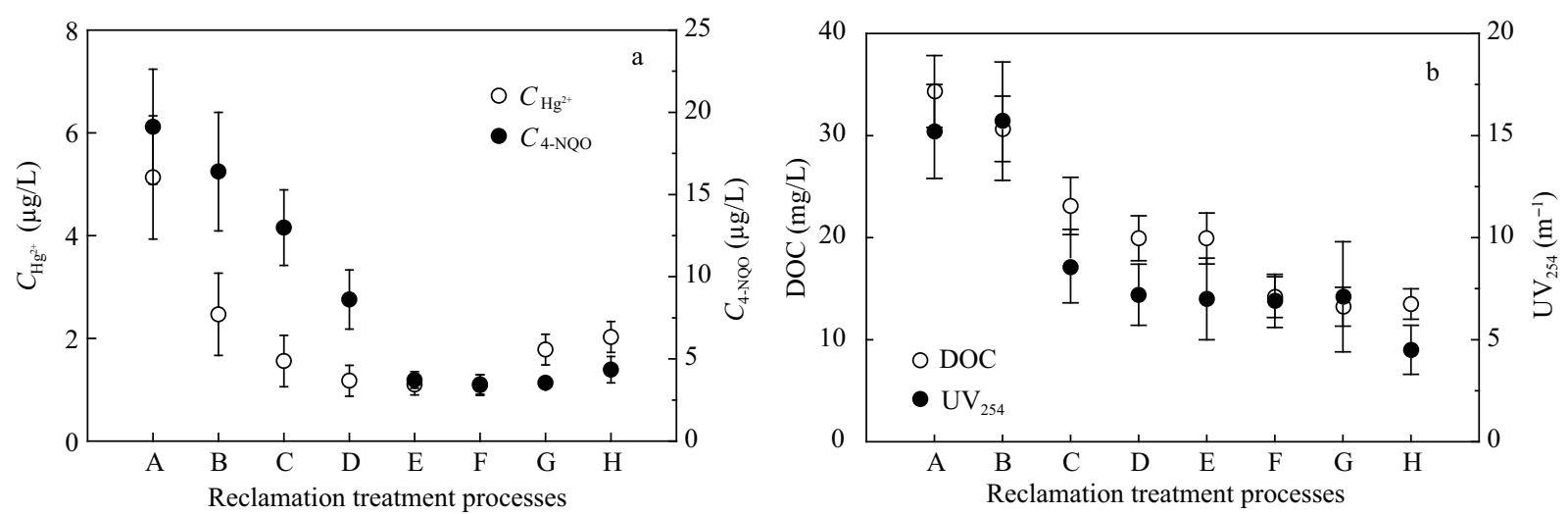

Fig. 2 (a) Changes of acute toxicity and genotoxicity during the reclamation treatment processes; (b) changes of DOC and UV 254 during the reclamation processes. a: influent, b: anaerobic process, C: anoxic process, D: oxic process, E: secondary effluent, F: ultrafiltration process, G: ozonation process, H: chlorination process. 
should be given to optimize the operational conditions of reclamation processes.

\subsection{Toxicity changes during ozonation process}

Figure 3 shows the toxicity variations as a function of ozone dosage and contact time. Both acute toxicity and genotoxicity decreased and stayed relatively stable after 10 min of contact time, and higher doses of ozone exhibited more significant and much quicker decreases of toxicity indices compared to lower doses. For $15 \mathrm{mg} / \mathrm{L}$ of ozone dose and $5 \mathrm{~min}$ contact time, $C_{\mathrm{Hg}^{2+}}$ acute toxicity decreased from 1.54 to $0.73 \mu \mathrm{g} / \mathrm{L}$, while $C_{4-\mathrm{NQO}}$ genotoxicity decreased from 6.08 to $1.82 \mu \mathrm{g} / \mathrm{L}$, which indicated that the ozonation process was more beneficial with respect to genotoxicity elimination than acute toxicity elimination (Cao et al., 2009). Under similar operational conditions, as shown in Fig. $3 c, U_{254}$ exhibited a significant decrease from 10.3 to $2.5 \mathrm{~m}^{-1}$, while DOC only showed a slight decrease (from 18.25 to $15.19 \mathrm{mg} / \mathrm{L}$ ) even at 15 $\mathrm{mg} / \mathrm{L}$ of ozone and $20 \mathrm{~min}$ of contact time (Fig. 3d). These experiments implied that the ozonation process could effectively oxidize unsaturated organic compounds into saturated compounds and eliminate the $\mathrm{UV}_{254}$ index (Andreozzi et al., 1999), while its mineralization was limited evidenced by a lower decrease of the DOC index, although some unsaturated compounds had changed into saturated ones (Rahman et al., 2010; Can and Çakir, 2010), which might cause an increase in genotoxicity due to the formation of toxic oxidation by-products (Stalter et al., 2010). Reungoat et al. (2010) investigated the relationship between the removal of micropollutants and biological effects during ozone-activated carbon processes, and found that the mixture of oxidation by-products had less toxic potential than the mixture of parent compounds. Whether the relatively significant decrease of genotoxicity during the ozonation process can be ascribed to the decrease of the $\mathrm{UV}_{254}$ index should be further explored.

\subsection{Toxicity changes during combined $\mathrm{O}_{3}-\mathrm{AC}$ process}

As mentioned above, the ozonation process could reduce toxicity indices and related organic compounds to a certain extent, but the residual toxicity was not insignificant due to its potential hazards for living organisms and even human health, and advanced purification is needed for safe reuse (Can and Çakir, 2010). Considering the large capacity of activated carbon for adsorbing organic compounds, a combination process composed of ozone and activated carbon $\left(\mathrm{O}_{3}-\mathrm{AC}\right)$ was investigated in previous studies (Reungoat et al., 2010). During pre-ozonation, the ozone doses were set to $0,5,10$ and $15 \mathrm{mg} / \mathrm{L}$, and the contact time was fixed at $15 \mathrm{~min}$, after which effluent was collected in a water-box to remove residual ozone, and then pumped into a fresh activated carbon column. Variations in toxicity indices and physicochemical indices during the combined

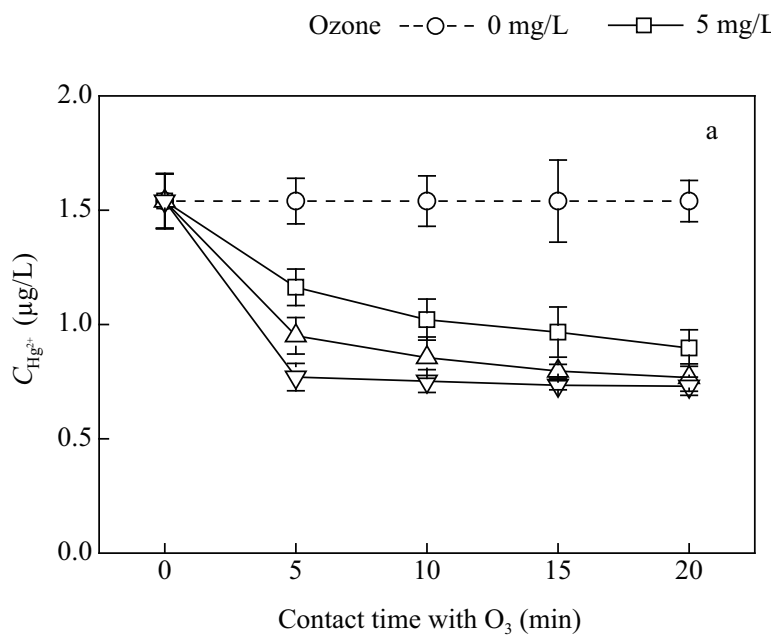

$\triangle-10 \mathrm{mg} / \mathrm{L} \quad \nabla-15 \mathrm{mg} / \mathrm{L}$
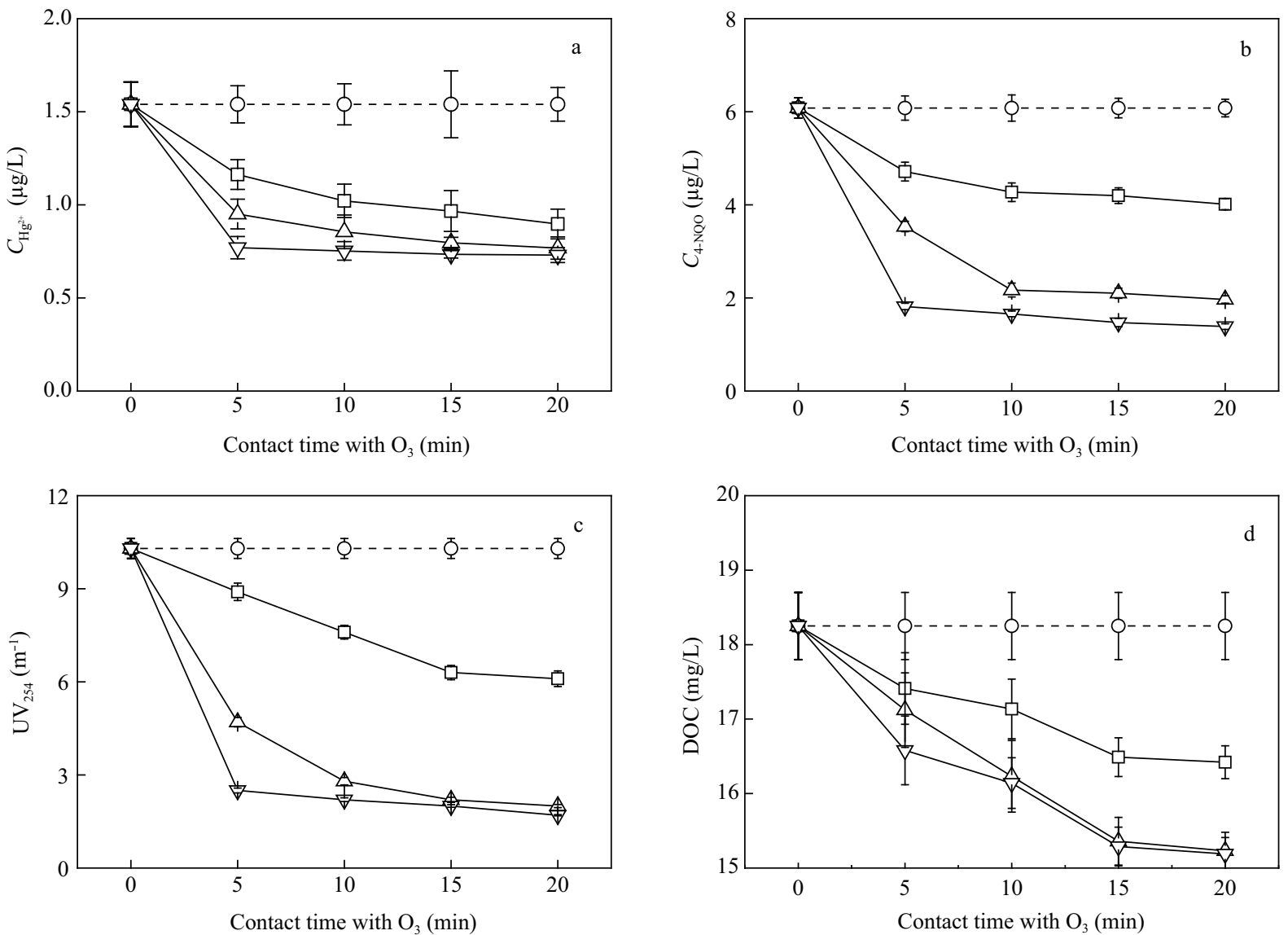

Fig. 3 Changes of toxicity indices and physicochemical indices in the $\mathrm{O}_{3}$ process. (a) $C_{\mathrm{Hg}^{2+}}$ for acute toxicity; (b) $C_{4-\mathrm{NQO}}$ for genotoxicity; (c) $\mathrm{UV}$ 254; (d) DOC. 
process are shown in Fig. 4. Taken together, all of the toxicity indices and physicochemical indices exhibited reduction trends as the retention time in the activated carbon column increased. Except for the DOC index, the removal percentages of all indices were more significant at lower doses of ozone than at higher doses; although the absolute values of all indices were still high after being treated with low doses of ozone, they were easily reduced during the subsequent activated carbon process. A $28 \%$ reduction of $C_{\mathrm{Hg}^{2+}}$ for acute toxicity was observed within $45 \mathrm{~min}$ of retention in the activated carbon column after a $0 \mathrm{mg} / \mathrm{L}$ preozonation process, while it was only $15 \%$ after a $5 \mathrm{mg} / \mathrm{L}$ pre-ozonation process (Fig. 4a). The removal percentage of $C_{4-\mathrm{NQO}}$ for genotoxicity was only $47 \%$ by the activated carbon column without pre-ozonation process, while it increased to $70 \%$ with the same pre-ozonation process (Fig. 4b). As for the $\mathrm{UV}_{254}$ index, the removal percentages were $30 \%$ with the activated carbon column after the preozonation process with 0 or $5 \mathrm{mg} / \mathrm{L}$ of ozone dose (Fig. $4 \mathrm{c}$ ). As for removal characteristics of DOC during the $\mathrm{O}_{3}-\mathrm{AC}$ combination process, pre-ozonation was not effective even with different ozone doses, and the elimination percentage with the activated carbon column was about $40 \%$ (Fig. 4d). The experiments also showed that the activated carbon did not thoroughly reduce the toxicity indices and $\mathrm{UV}_{254}$ index to zero for samples treated with high ozone doses (10 and $15 \mathrm{mg} / \mathrm{L}$ ) and there was still a certain amount of residues in the effluent (Randtke and Snoeyink, 1983).

\subsection{Toxicity changes during chlorination process}

Chlorination is an important process for reclamation and safe reuse of wastewater although it presents a potential risk for formation of disinfection by-products (Wang et al., 2005). The changes in the toxicity and physicochemical indices during chlorination of the effluents of the ozonation and combined $\mathrm{O}_{3}-\mathrm{AC}$ processes were also investigated, and the results are shown in Figs. 5 and 6. It can be seen that, with increasing chlorine dose, the $C_{\mathrm{Hg}^{2+}}$ acute toxicity had a $60 \%$ increase with a $0 \mathrm{mg} / \mathrm{L}$ pre-ozonation process, and about $40 \%$ with a $5 \mathrm{mg} / \mathrm{L}$ pre-ozonation process; there was almost no increase of $C_{\mathrm{Hg}^{2+}}$ for 10 and $15 \mathrm{mg} / \mathrm{L}$ preozonation processes. Compared with the acute toxicity, with increasing chlorine dose, the genotoxicity index had a slight increase (ca. 17\%) with a $0 \mathrm{mg} / \mathrm{L}$ pre-ozonation process, about $12 \%$ with a $5 \mathrm{mg} / \mathrm{L}$ pre-ozonation process, and no increase for 10 and $15 \mathrm{mg} / \mathrm{L}$ pre-ozonation processes. As for the combined $\mathrm{O}_{3}$-AC process, the following chlorination process elevated the genotoxicity of water samples, and the $C_{4-\mathrm{NQO}}$ increased by $0.2 \mu \mathrm{g} / \mathrm{L}$ after adding $12 \mathrm{mg} / \mathrm{L}$ of chlorine to the $\mathrm{O}_{3}$-AC system with different ozone doses $(0,5,10$, and $15 \mathrm{mg} / \mathrm{L})$. As shown in Fig. $5 \mathrm{c}$, the chlorination process did not cause changes in DOC for water samples which had gone through the pre-ozonation process. However, with the addition of chlorine, the $\mathrm{UV}_{254}$ showed a small increase (ca. 22\%) for water samples treated with a $0 \mathrm{mg} / \mathrm{L}$ pre-ozonation process, while there were

Ozone --O-- $0 \mathrm{mg} / \mathrm{L} \quad \square-5 \mathrm{mg} / \mathrm{L} \quad \triangle-10 \mathrm{mg} / \mathrm{L} \quad \longrightarrow-15 \mathrm{mg} / \mathrm{L}$
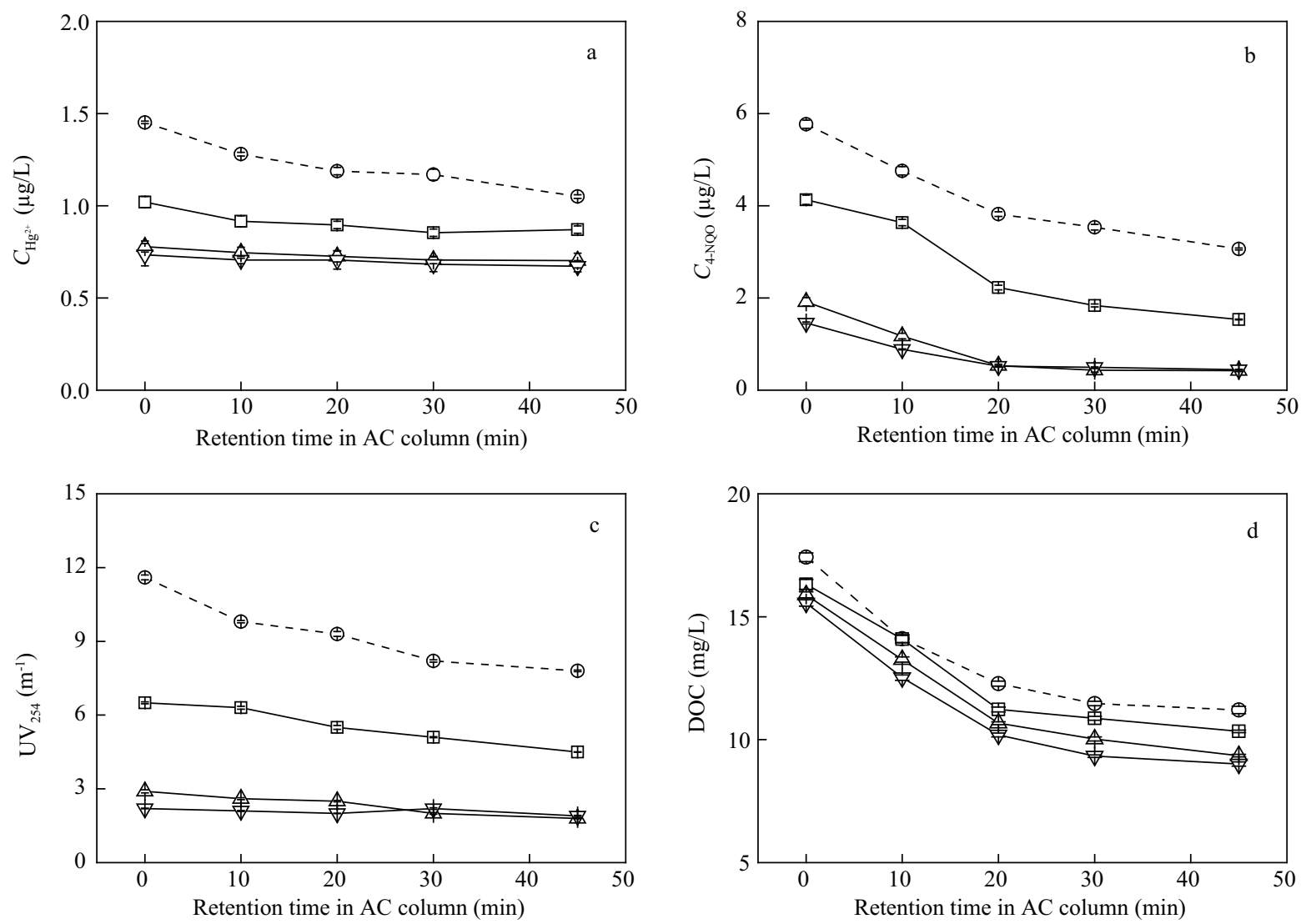

Fig. 4 Changes of toxicity indices and physicochemical indices during the $\mathrm{O}_{3}$-AC process. (a) $C_{\mathrm{Hg}^{2}}$ acute toxicity, (b) $C_{4-\mathrm{NQO}}$ genotoxicity, (c) DOC, and (d) $\mathrm{UV}_{254}$. 
Ozone $--\mathrm{O}-0 \mathrm{mg} / \mathrm{L} \quad \square-5 \mathrm{mg} / \mathrm{L} \quad \triangle 10 \mathrm{mg} / \mathrm{L} \quad \square-15 \mathrm{mg} / \mathrm{L}$
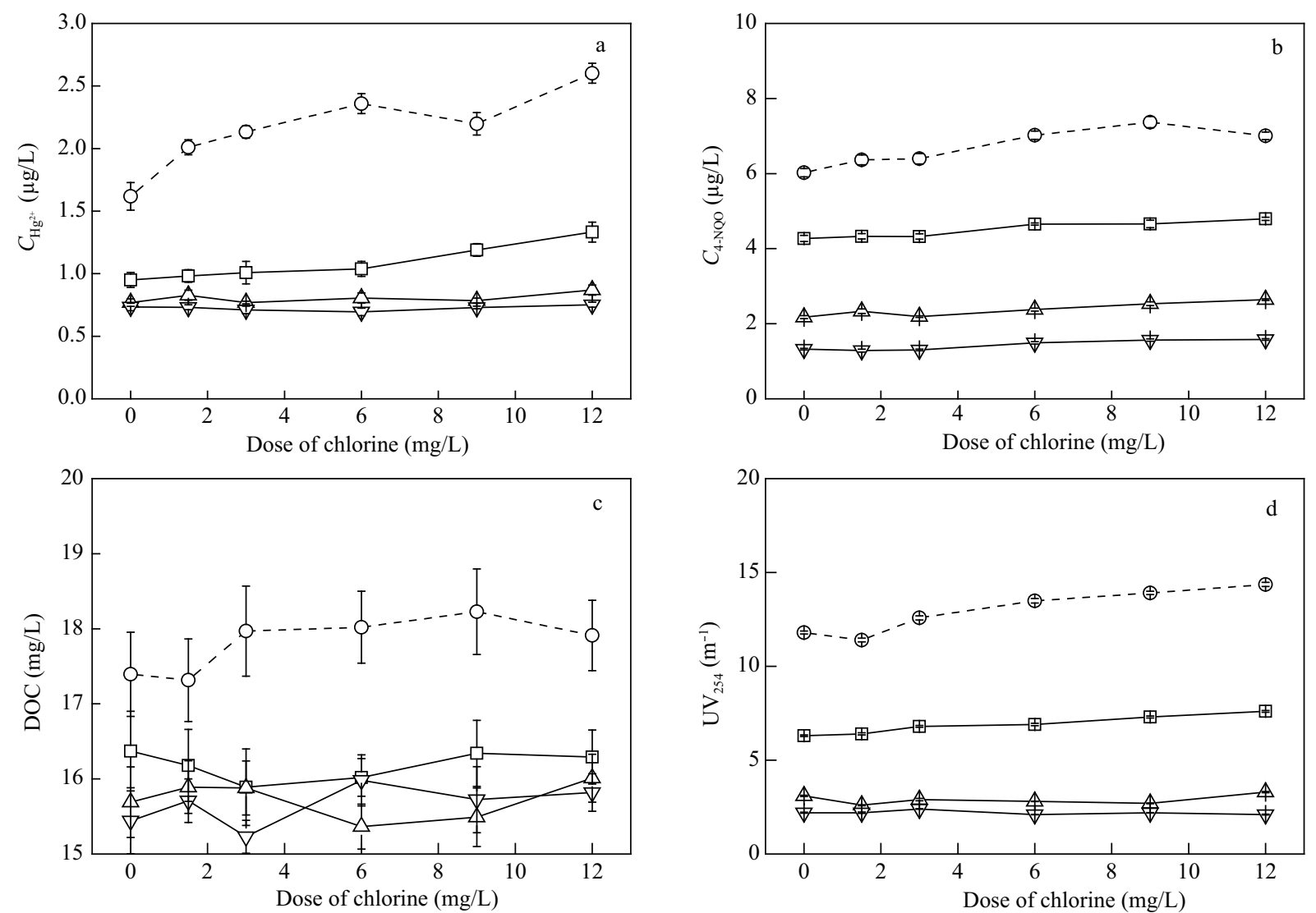

Fig. 5 Changes of toxicity indices and physicochemical indices due to chlorination following the $\mathrm{O}_{3}$ process. (a) $C_{\mathrm{Hg}^{2+}}$ acute toxicity; (b) $C_{4-\mathrm{NQO}}$ genotoxicity; (c) DOC; (d) $\mathrm{UV}_{254}$.
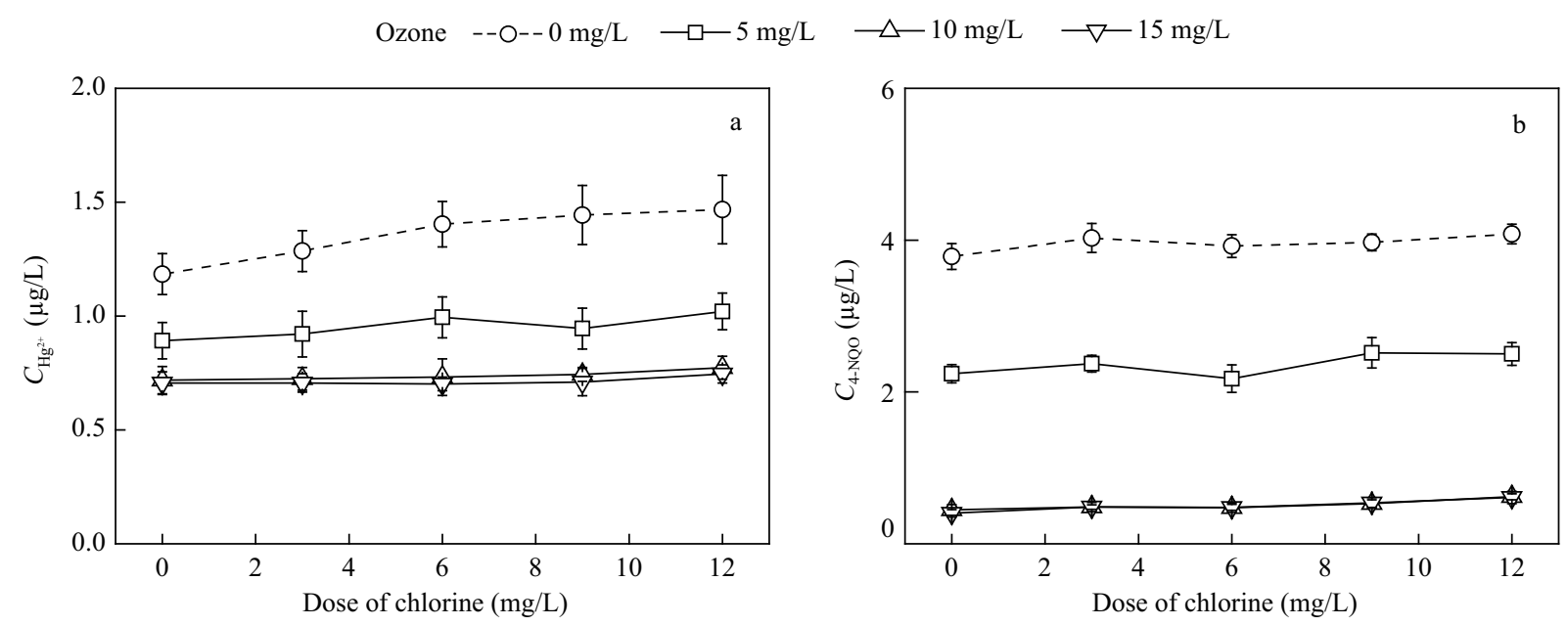

Fig. 6 Changes of $C_{\mathrm{Hg}^{2+}}$ acute toxicity (a) and $C_{4-\mathrm{NQO}}$ genotoxicity (b) due to chlorination following the combined $\mathrm{O}_{3}$-AC process.

not any changes to $\mathrm{UV}_{254}$ for water samples pretreated with 5,10 and $15 \mathrm{mg} / \mathrm{L}$ of ozone due to its strong oxidation of unsaturated functional groups in organic compounds (Fig. 5d). These experiments implied that pre-ozonation inhibits the formation of toxic disinfection by-products and ensures the low toxicity of effluents, and the combined $\mathrm{O}_{3}$-AC process exhibits more advantages, especially for pre-ozonation with a high dose of ozone, such as 10 or $15 \mathrm{mg} / \mathrm{L}$, which was attributed to the decomposition of precursors of disinfection by-products (Yang et al., 2005; Marhaba and Van, 1999).

\subsection{Correlation between toxicity and physicochemical parameters}

In recent years, more and more researchers have focused attention on developing and using toxicity tests in evaluating the safety of water or the performance of wastewater treatment processes due to their direct, clear, and integrated description of co-existing toxic compounds in water. After all, the conventional physicochemical indices such as DOC and $U_{254}$ are relatively easy to acquire compared to toxicity indices, so the possibility of predicting or presenting a surrogate for the toxicity characteristics of 
water using physicochemical indices is attractive. In the present study, a total of 65 water samples collected from the $\mathrm{A}^{2} \mathrm{O}$ wastewater treatment and reclamation treatment processes were defined as a training set, and correlation analyses among the toxicity indices and physicochemical indices were conducted, with the results shown in Fig. $7 \mathrm{a}-\mathrm{c}$. It can be seen that the genotoxicity index had a degree of correlation to DOC $\left(R^{2}=0.7443\right)$, while the acute toxicity index had an insignificant correlation to DOC $\left(R^{2}=0.4937\right)$. Both genotoxicity and acute toxicity indices were correlated with $\mathrm{UV}_{254}\left(R^{2}=0.6322\right.$ and 0.6363 , respectively). In order to reveal the correlation between toxicity indices and physicochemical indices for different wastewater treatment/reclamation processes, the water samples were respectively explored according to the different processes. As for $\mathrm{A}^{2} \mathrm{O}$ wastewater treatment processes (Fig. 7d, e), the genotoxicity index $C_{4-\mathrm{NQO}}$ had a good correlation with the DOC index $\left(R^{2}=0.904\right)$ and some degree of correlation with the $U_{254}$ index $\left(R^{2}=0.7569\right)$. There were no significant relationships between toxicity indices and physicochemical indices for the ozonation process (Fig. $7 \mathrm{~g}, \mathrm{~h}$ ), while both the genotoxicity and acute toxicity indices had significant correlation with the $\mathrm{UV}_{254}$ index $\left(R^{2}=0.9726\right.$ and 0.9106$)$ for the combined $\mathrm{O}_{3}$-AC process (Fig. 7j, k). In particular, for the chlorination process (Fig. $7 \mathrm{~m}, \mathrm{n}$ ), both the genotoxicity and acute toxicity indices had good relationships (all of $R^{2}$ were more than 0.8 ) with the physicochemical indices DOC and $U_{254}$. The correlation analyses suggested that $\mathrm{UV}_{254}$ had relatively higher correlation with both acute
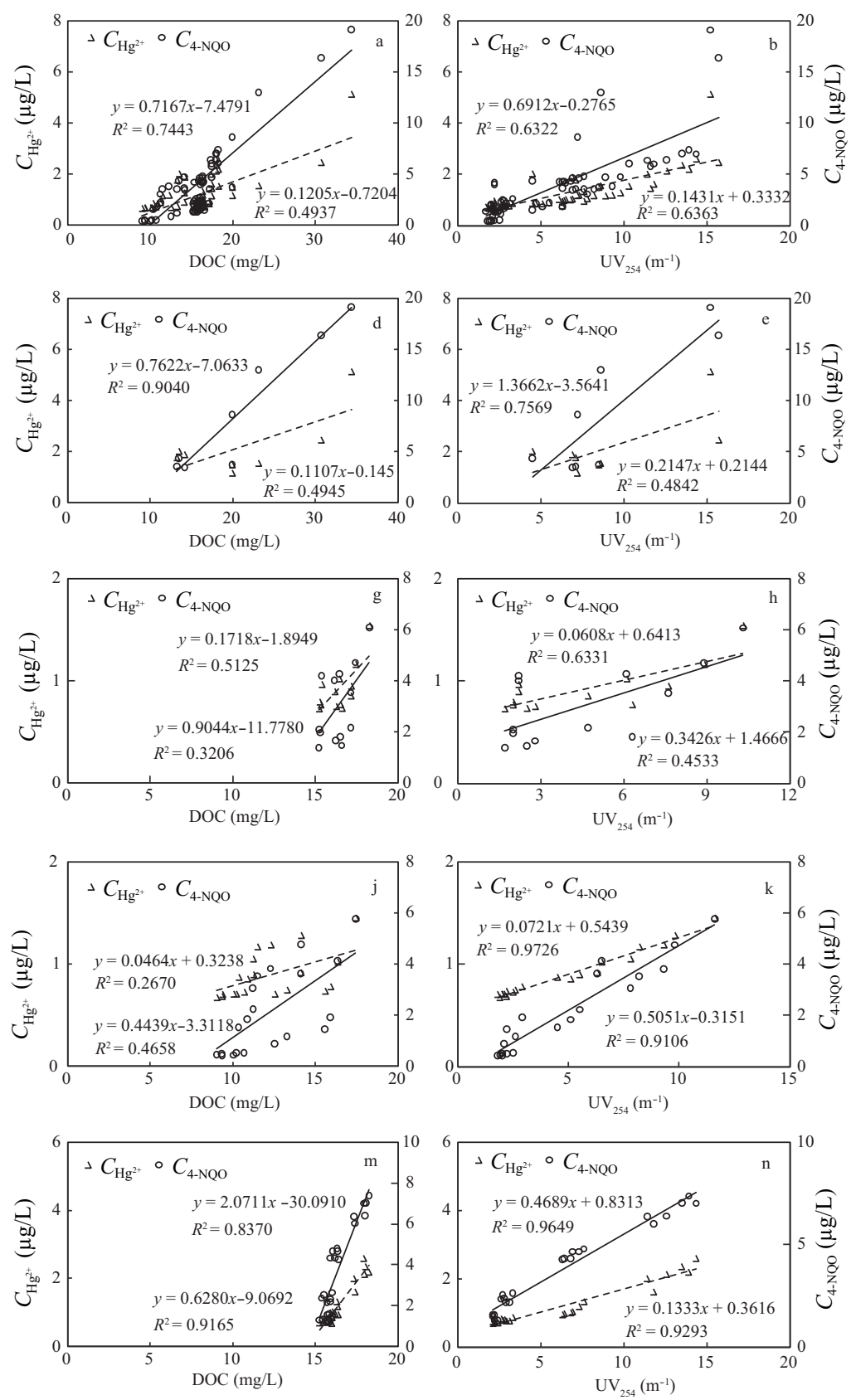
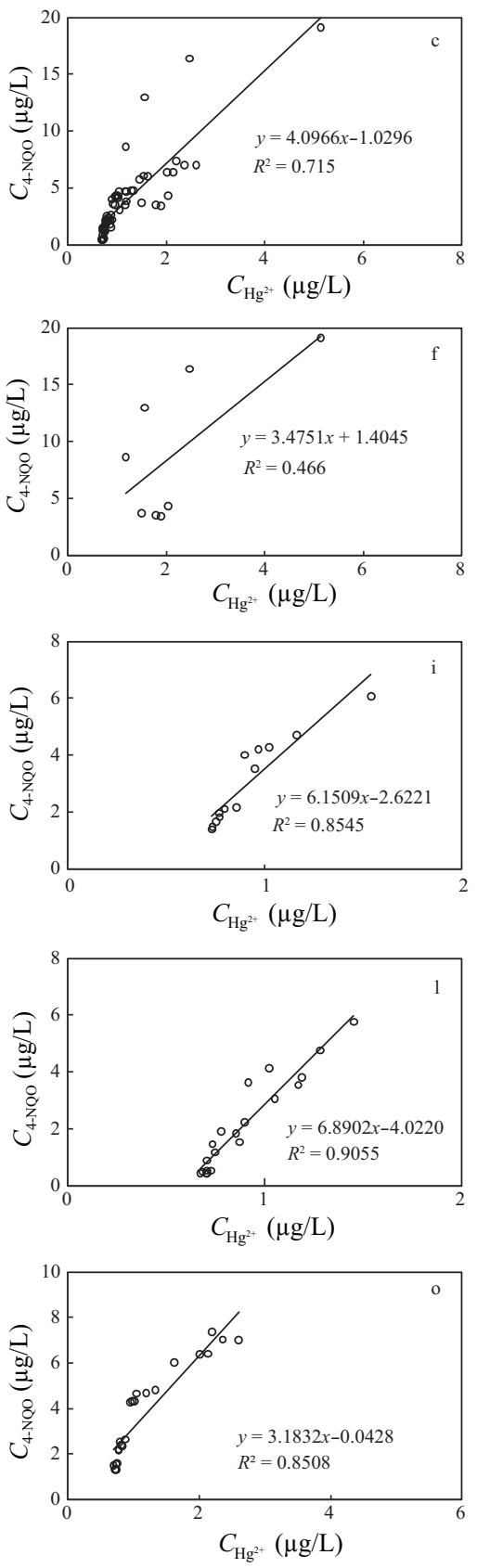

Fig. 7 Correlation analyses among the toxicity indices and physicochemical indices. (a, b, c) all samples treated with various processes; (d, e, f) traditional wastewater treatment processes; $(\mathrm{g}, \mathrm{h}, \mathrm{i})$ ozonation process; $(\mathrm{j}, \mathrm{k}, \mathrm{l})$ combined ozone and activated carbon process; (m, $\mathrm{n}$, o) chlorination process. 
toxicity and genotoxicity indices than did DOC for most of the water samples (Wei et al., 2006). In addition, there was good relationship between $C_{\mathrm{Hg}^{2+}}$ and $C_{4-\mathrm{NQO}}$ for all reclamation treatment processes (Fig. 7c, i, 1, and o) with the exception of traditional wastewater treatment processes (Fig. 7f).

\section{Conclusions}

It can be concluded that: (1) The $\mathrm{A}^{2} \mathrm{O}$ wastewater treatment processes could reduce both the physicochemical indices and toxicity indices to some extent, while the effluent still exhibited some toxicity effects which would limit potential reuse applications of reclaimed water. (2) The ozonation process alone had less effectiveness in decreasing the DOC index and toxicity indices. (3) The combined $\mathrm{O}_{3}$-AC process appeared to have good removal capability not only for DOC and $\mathrm{UV}_{254}$ indices, but also for toxicity indices, which may be attributed to the high oxidation potential of $\mathrm{O}_{3}$ and strong adsorption capability of activated carbon. (4) The chlorination process (after ozonation with and without activated carbon) did not change the values of DOC and $\mathrm{UV}_{254}$ indices, but increased the acute toxicity and genotoxicity more or less, which may be attributed to the formation of chlorinated disinfection by-products. (5) Relatively high correlations were found between $\mathrm{UV}_{254}$ and toxicity indices for most water samples, which implied that, to a certain extent, it is feasible to evaluate the safety of water quality and effectiveness of wastewater treatment and reclamation processes using traditional physicochemical parameters; however, combining the toxicity indices with physicochemical parameters could provide an additional safeguard for water reuse applications.

\section{Acknowledgments}

This work was supported by the National High Technology Research and Development Program (863) of China (No. 2008AA062502, 2009AA063901), and the National Natural Science Foundation of China (No. 20877090, 50938004).

\section{References}

Andreozzi R, Caprio V, Insola A, Marotta R, 1999. Advanced oxidation processes (AOP) for Water purification and recovery. Catalysis Today, 53(1): 51-59.

Araújo C V M, Nascimento R B, Oliveira C A, Strotmann U J, da Silva E M, 2005. The use of Microtox to assess toxicity removal of industrial effluents from the industrial district of Camaçari (BA Brazil). Chemosphere, 58(9): 1277-1281.

Asano T, Burton F L, Leverenz H L, Tsuchihashi R, Tchobanoglous G, 2007. Water Reuse-Issues, Technologies, and Applications. McGraw-Hill, New York.

Can Z S, Çakir E, 2010. Treatability of organic constituents in the paşköy wastewater treatment plant effluent by $\mathrm{O}_{3}$ and $\mathrm{O}_{3} / \mathrm{H}_{2} \mathrm{O}_{2}$. Ozone Science $\mathcal{E}$ Engineering, 32(3): 209214.

Cao N, Yang M, Zhang Y, Hu J Y, Ike M, Hirotsuji J et al., 2009. Evaluation of wastewater reclamation technologies based on in vitro and in vivo bioassays. Science of the Total Environment, 407(5): 1588-1597.

Chu J Y, Chen J N, Wang C, Fu P, 2004. Wastewater reuse potential analysis: implications for China's water resources management. Water Research, 38(11): 2746-2756.

Economou A, Botitsi H, Antoniou S, Tsipi D, 2009. Determination of multi-class pesticides in wines by solid-phase extraction and liquid chromatography-tandem mass spectrometry. Journal of Chromatography A, 1216(31): 5856-5867.

Fernández M D, Cagigal E, Vega M M, Urzelai A, Babín M, Pro $\mathrm{J}$ et al., 2005. Ecological risk assessment of contaminated soils through direct toxicity assessment. Ecotoxicology and Environmental Safety, 62(2): 174-184.

Hernando M D, Fernández-Alba A R, Tauler R, Barceló D, 2005. Toxicity assays applied to wastewater treatment. Talanta, 65(2): 358-366.

Hu H Y, Wei D B, Dong C H, 2002. Assessment and management on water quality safety of sewage. Environmental Protection, (11): 37-38.

Huerta-Fontela M, Galceran M T, Ventura F, 2010. Fast liquid chromatography - quadrupole-linear ion trap mass spectrometry for the analysis of pharmaceuticals and hormones in water resources. Journal of Chromatography A, 1217(25): 4212-4222.

ISO13829, 2000. International standard: water qualitydetermination of the genotoxicity of water and waste water using the umu-test. ISO, Geneva, Switzerland.

Juvonen R, Martikainen E, Schultz E, Joutti A, Ahtiainen J, Lehtokari M, 2000. A battery of toxicity tests as indicators of decontamination in composting oily waste. Ecotoxicology and Environmental Safety, 47(2): 156-166.

Katsoyiannis A, Samara C, 2007. Ecotoxicological evaluation of the wastewater treatment process of the sewage treatment plant of Thessaloniki, Greece. Journal of Hazardous Materials, 141(3): 614-621.

Macova M, Escher B I, Reungoat J, Carswell S, Chue K L, Keller J et al., 2010. Monitoring the biological activity of micropollutants during advanced wastewater treatment with ozonation and activated carbon filtration. Water Research, 44(2): 477-492.

Marhaba T F, Van D, 1999. Chlorinated disinfection by-product formation potential of dissolved organic matter fractions at an ozonation water treatment plant. Advances in Environmental Research, 3: 255-268.

Mendonça E, Picado A, Paixão S M, Silva L, Cunha M A, Leitão $S$ et al., 2009. Ecotoxicity tests in the environmental analysis of wastewater treatment plants: Case study in Portugal. Journal of Hazardous Materials, 163(2-3): 665670.

Oda Y, Nakamura S I, Oki I, Kato T, Shinagawa H, 1985. Evaluation of the new system (umu-test) for the detection of environmental mutagens and carcinogens. Mutation Research, 147(5): 219-229.

Pedrouzo M, Borrull F, Pocurull E, Marcé R M, 2009. Estrogens and their conjugates: Determination in water samples by solid-phase extraction and liquid chromatography-tandem mass spectrometry. Talanta, 78(4-5): 1327-1331.

Rahman M F, Jasim S Y, Yanful E K, Ndiongue S, Borikar D, 2010. Advanced oxidation treatment of drinking water: Part II. Turbidity, particles and organics removal from Lake Huron water. Ozone Science $\mathcal{E}$ Engineering, 32(5): 295304.

Ramos J J, Gómara B, Fernández M A, González M J, 2007. A simple and fast method for the simultaneous determination 
of polychlorinated biphenyls and polybrominated diphenyl ethers in small volumes of human serum. Journal of Chromatography A, 1152(1-2): 124-129.

Randtke S J, Snoeyink V L, 1983. Evaluating GAC adsorptive capacity. Journal of the American Water Works Association, 75(8): 406-413.

Reungoat J, Macova M, Escher B I, Carswell S, Mueller J F, Keller J, 2010. Removal of micropollutants and reduction of biological activity in a full scale reclamation plant using ozonation and activated carbon filtration. Water Research, 44(2): 625-637.

Sánchez-Polo M, Salhi E, Rivera-Utrilla J, von Gunten U, 2006. Combination of ozone with activated carbon as an alternative to conventional advanced oxidation processes. Ozone Science $\mathcal{E}$ Engineering, 28(4): 237-245.

SEPA, 1995. Water quality-Determination of the acute toxicityLuminescent bacteria test GB/T15441-1995. State Environmental Protection Administration, China.

Stalter D, Magdeburg A, Oehlmann J, 2010. Comparative toxicity assessment of ozone and activated carbon treated sewage effluents using an in vivo test battery. Water Research, 44(8): 2610-2620.

Takanashi H, Mayumi M, Kato M, Hirata M, Hano T, 2002. Removal of mutagen precursor from wastewater by activated sludge and oxidation treatment. Water Science and Technology, 46(11-12): 389-394.

UKEA, 2006. Integrated pollution prevention \& control (IPPC)-
Guidance on the use of direct toxicity assessment in PPC impact assessments. UK Environment Agency, Version 1.

US EPA (US Environmental Protection Agency), 1991. Technical support document for water quality-based control EPA505/2-90-001. Office of Water, USEPA, Washington DC. 335.

Vazquez-Roig P, Andreu V, Blasco C, Picó Y, 2010. SPE and LC-MS/MS determination of 14 illicit drugs in surface waters from the Natural Park of L'Albufera (València, Spain). Analytical and Bioanalytical Chemistry, 397(7): 2851-2864.

Wang L S, Hu H Y, Zhang T, 2005. Comparison study on changes in water quality and toxicity of wastewater after chlorine and chlorine dioxide disinfections. Future of Urban Wastewater Systems - Decentralisation and Reuse, 677-683.

Wei D B, Wang L S, Wei J, Hu H Y, 2006. Effects of chlorine disinfection on toxicity formation in reclaimed water. Bulletin of Environmental Contamination and Toxicology, 76(2): 226-232.

World Bank, 2009. Addressing China's Water Scarcity: Recommendations for Selected Water Resource Management Issues. World Bank, Washington DC. 1-143.

Yang C, Xu Y R, Teo K C, Goh N K, Chia L S, Xie R J, 2005. Destruction of organic pollutants in reusable wastewater using advanced oxidation technology. Chemosphere, 59(3): $441-445$. 